\title{
Synthesis and characterization of Schiff's bases of sulfamethoxazole
}

\author{
Zainab Hussain ${ }^{1}$, Emad Yousif ${ }^{2 *}$, Ahmed Ahmed $^{2}$ and Ali Altaie
}

\begin{abstract}
Background: Schiff's bases are excellent ligands which are synthesized from the condensation of primary amines with carbonyl groups.

Findings: The classical reaction for the synthesis of Schiff's bases in an ethanolic solution and glacial acetic acid as a catalyst was followed in the synthesis of substituted sulfamethoxazole compounds.

Conclusions: Some Schiff's bases containing sulfamethoxazole nucleus have been synthesized and characterized. The present compounds are hoped to be applied in the photostability of PVC.
\end{abstract}

Keywords: Schiff bases; Sulfamethoxazole; Synthesis

\section{Findings}

\section{Background}

Schiff's bases are an important class of organic compounds [1]. They were first reported by Hugo Schiff in 1864 [2]. Schiff's bases are condensation products of primary amines with carbonyl compounds. The common structural feature of these compounds is the azomethine group with the general formula $\mathrm{RHC}=\mathrm{N}-\mathrm{R}_{1}$, where $\mathrm{R}$ and $R_{1}$ are alkyl, aryl, cycloalkyl, or heterocyclic groups [1]. Structurally, a Schiff's base (also known as imine or azomethine) is a nitrogen analogue of an aldehyde or ketone in which the carbonyl group $(>\mathrm{C}=\mathrm{O})$ is replaced by an imine or azomethine group. Schiff's bases have also been shown to exhibit a broad range of biological activities, including antifungal, antibacterial, antimalarial, antiproliferative, anti-inflammatory, antiviral, and antipyretic properties [3,4]. Imine or azomethine groups are present in various natural, naturally derived, and nonnatural compounds. The imine group present in such compounds has been shown to be critical to their biological activities [5-7]. Schiff's bases are important compounds owing to their wide range of industrial applications [8]. Schiff's bases are used in the photostabilization of poly (vinyl chloride) polymers against photodegradation by

\footnotetext{
* Correspondence: emad_yousif@hotmail.com

${ }^{2}$ Department of Chemistry, College of Science, Al-Nahrain University, Baghdad, Iraq

Full list of author information is available at the end of the article
}

ultraviolet radiation [9-11] and are also used to improve poly(methyl methacrylate) from degradation [12] and to prevent polystyrene from photodegradation by their addition to polymer films $[13,14]$.

\section{Methods}

Fourier transform infrared (FTIR) spectra were registered on a SHIMADZU (8300, Kyoto, Japan) infrared spectrophotometer, using $\mathrm{KBr}$ discs. Proton nuclear magnetic resonance $\left({ }^{1} \mathrm{H}-\mathrm{NMR} ; 600 \mathrm{MHz}\right)$ spectra were obtained at room temperature with Bruker equipment (Madison, WI, USA) using TMS as an internal standard in dimethyl sulfoxide (DMSO). Melting points were recorded using hot-stage Gallenkamp melting point apparatus (Loughborough, UK) and were uncorrected. Analytical grade chemicals (BDH, G.C.C., Hopkin \& William Corporation, Poole, UK) were used throughout the project.

\section{Results and discussion}

The synthesis of Schiff's bases with different specific aldehydes in ethanol as a solvent and catalyst (glacial acetic acid) resulted in five new series of Schiff's bases with the general formula $\mathrm{RHC}=\mathrm{N}-\mathrm{R}_{1}$. Here $\mathrm{R}_{1}=$ sulfamethoxazole and $\mathrm{R}=$ benzaldehyde, 4-bromobenzaldehyde, 2-hydroxybenzaldehyde (salicylaldehyde), 4-N,N-dimethylbenzaldehyde, and 3-nitrobenzaldehyde were synthesized by the reaction of sulfamethoxazole and substituted 
aldehydes in ethanol (Scheme 1). Such compounds were characterized by different physicochemical techniques like melting point, elemental analysis, FTIR spectroscopy, and multinuclear NMR $\left({ }^{1} \mathrm{H}\right)$.

\section{Physical properties of the prepared Schiff's bases}

The physical properties of sulfamethoxazole and its derivatives including melting point, color, and elemental analysis are tabulated in Table 1.
The structure of the prepared Schiff's bases was confirmed by infrared spectroscopy. The FTIR spectra of sulfamethoxazole and its prepared compounds, as shown in Table 2, showed that the band of $\mathrm{NH}_{2}$ was found in sulfamethoxazole in the location $3,298 \mathrm{~cm}^{-1}$ and then vanished. After that, the band of $\mathrm{NH}$ appeared in the prepared Schiff's bases with different shifting from 3,250 to $3,287 \mathrm{~cm}^{-1}$. The band of $\mathrm{C}=\mathrm{N}$ for imine stretching vibration was also not found in sulfamethoxazole, and it

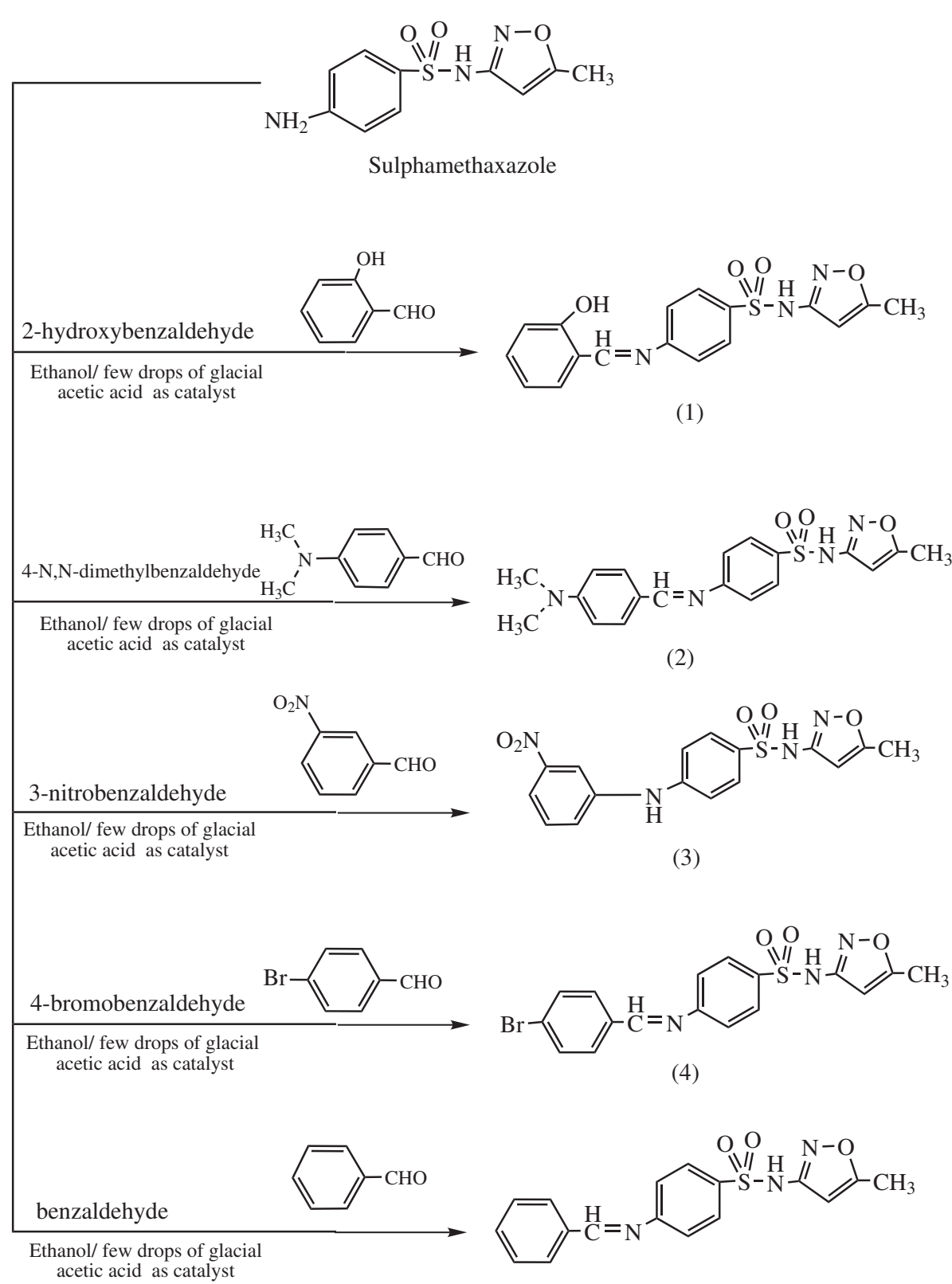

Scheme 1 Scheme of the preparation of Schiff's bases from sulfamethoxazole. (1) 4-[(2-Hydroxy-benzylidene)-amino]-N-(5-methyl-isoxazol-3-yl)benzene sulfonamide. (2) N-(5-Methyl-isoxazol-3-yl)-4-[(4-nitroox-benzylidene)-amino]-benzene sulfonamide. (3) 4-[(4-Dimethylamino-benzylidene)-amino]$\mathrm{N}$-(5-methyl-isoxazol-3-yl)-benzene sulfonamide. (4) 4-[(4-Bromo-benzylidene)-amino]-N-(5-methyl-isoxazol-3-yl)-benzene sulfonamide. (5) (N-(5-Methyl-isoxazol-3-yl)-4-[(3-nitro-benzylidene)-amino]-benzene sulfonamide. 
Table 1 Physical data of the prepared compounds

\begin{tabular}{|c|c|c|c|c|c|c|c|}
\hline \multirow[t]{2}{*}{ Compounds } & \multirow[t]{2}{*}{ Color } & \multirow[t]{2}{*}{$\begin{array}{l}\text { MP } \\
\left({ }^{\circ} \mathrm{C}\right)\end{array}$} & \multicolumn{5}{|c|}{$\begin{array}{l}\text { Elemental analysis, } \\
\text { theoretical (actual) }\end{array}$} \\
\hline & & & $\%$ C & $\% \mathrm{H}$ & $\% \mathrm{~N}$ & $\% 0$ & $\% \mathrm{~S}$ \\
\hline \multirow[t]{2}{*}{ (1) } & \multirow[t]{2}{*}{ Yellow } & \multirow{2}{*}{$\begin{array}{l}190 \text { to } \\
192\end{array}$} & 57.13 & 4.23 & 11.76 & 17.91 & 8.97 \\
\hline & & & $(57.23)$ & (4.88) & (10.39) & (16.88) & $(9.11)$ \\
\hline \multirow[t]{2}{*}{ (2) } & \multirow[t]{2}{*}{ Brown } & \multirow{2}{*}{$\begin{array}{l}148 \text { to } \\
150\end{array}$} & 60.85 & 6.23 & 13.52 & 11.58 & 7.74 \\
\hline & & & $(59.82)$ & (6.43) & (13.63) & (12.09) & $(8.10)$ \\
\hline \multirow[t]{2}{*}{ (3) } & \multirow[t]{2}{*}{ Orange } & \multirow{2}{*}{$\begin{array}{l}122 \text { to } \\
124\end{array}$} & 52.84 & 3.65 & 14.50 & 20.70 & 8.30 \\
\hline & & & (53.88) & (3.22) & (13.91) & (19.33) & $(8.21)$ \\
\hline \multirow[t]{2}{*}{ (4) } & \multirow{2}{*}{$\begin{array}{l}\text { Light } \\
\text { yellow }\end{array}$} & \multirow{2}{*}{$\begin{array}{l}142 \text { to } \\
143\end{array}$} & 48.58 & 3.36 & 10.00 & 11.42 & 7.63 \\
\hline & & & (49.59) & (3.51) & (9.33) & $(10.21)$ & (8.33) \\
\hline \multirow[t]{2}{*}{ (5) } & \multirow[t]{2}{*}{ Orange } & \multirow{2}{*}{$\begin{array}{c}110 \text { to } \\
112\end{array}$} & 59.81 & 4.43 & 12.31 & 14.06 & 9.39 \\
\hline & & & (69.88) & (3.89) & (12.49) & (14.63) & $(10.21)$ \\
\hline
\end{tabular}

appeared in the prepared Schiff's bases with shifting from 1,603 to $1,650 \mathrm{~cm}^{-1}$. Also, the band of $\mathrm{C}=\mathrm{N}$ for ring stretching vibration shifted from $1,620 \mathrm{~cm}^{-1}$ in sulfamethoxazole to 1,615 to $1,630 \mathrm{~cm}^{-1}$ in the prepared compounds.

The ultraviolet-visible spectrophotometry technique is used to characterize sulfamethoxazole and its derivatives in DMSO as a solvent. The ultraviolet-visible electronic spectra of the prepared Schiff's bases showed absorption bands that could be attributed to $\pi \rightarrow \pi *$ electronic transitions; these transitions are assigned in relevance to the structures of the compounds. The electronic spectrum of sulfamethoxazole shows a band at the wavelength $280 \mathrm{~nm}$; this may be attributed to the $\pi \rightarrow \pi^{*}$ electronic transition. In the prepared Schiff's bases, the bands shifted to wavelengths different from that of the corresponding band in sulfamethoxazole, as shown in Table 3, which appear in the wavelength range between 270 and $360 \mathrm{~nm}$. These transitions may be attributed to $\pi \rightarrow \pi^{*}$ and $n \rightarrow \pi^{*}$ electronic transitions.

The ${ }^{1} \mathrm{H}$-NMR spectrum of compound (1) showed the following characteristic chemical shifts (DMSO as a solvent): the singlet signal at $\delta=2.212 \mathrm{ppm}$ suggested

Table 2 FTIR spectroscopy for sulfamethoxazole and its derivatives

\begin{tabular}{lcccc}
\hline Compounds & $\begin{array}{c}\boldsymbol{v}\left(\mathrm{NH}_{2}\right) \\
\left(\mathbf{c m}^{-1}\right)\end{array}$ & $\begin{array}{c}\boldsymbol{v}(\mathrm{N}-\mathrm{H}) \\
\left(\mathbf{c m}^{-1}\right)\end{array}$ & $\begin{array}{c}\boldsymbol{v}(\mathrm{C}=\mathrm{N}) \text { imine } \\
\left(\mathbf{c m}^{-1}\right)\end{array}$ & $\begin{array}{c}\boldsymbol{v}(\mathrm{C}=\mathrm{N}) \text { ring } \\
\left(\mathbf{c m}^{-1}\right)\end{array}$ \\
\hline Sulfamethoxazole & 3,298 & - & - & 1,620 \\
$(1)$ & - & 3,250 & 1,650 & 1,616 \\
$(2)$ & - & 3,266 & 1,603 & 1,620 \\
$(3)$ & - & 3,290 & 1,650 & 1,600 \\
$(4)$ & - & 3,270 & 1,650 & 1,630 \\
$(5)$ & - & 3,287 & 1,633 & 1,615 \\
\hline
\end{tabular}

Table 3 UV spectroscopy for sulfamethoxazole and its derivatives

\begin{tabular}{lcc}
\hline Compounds & Absorption bands (nm) & Assigned transition \\
\hline Sulfamethoxazole & 280 & $\pi \rightarrow \pi^{*}$ \\
$(1)$ & 282,310 & $\pi \rightarrow \pi^{*}, n \rightarrow \pi^{*}$ \\
$(2)$ & 250,360 & $\pi \rightarrow \pi^{*}, n \rightarrow \pi^{*}$ \\
(3) & 270 & $\pi \rightarrow \pi^{*}$ \\
$(4)$ & 271 & $\pi \rightarrow \pi^{*}$ \\
(5) & 270 & $\pi \rightarrow \pi^{*}$ \\
\hline
\end{tabular}

the attribution of the protons of the $\mathrm{CH}_{3}$ group, the singlet signal at $\delta=6.029 \mathrm{ppm}$ suggested the attribution of the proton of $\mathrm{CH}$ of the isoxazole ring, the multiplet signal at $\delta=6.743$ to $7.768 \mathrm{ppm}$ suggested the attribution of the protons of two aromatic benzene rings, the singlet signal at $\delta=8.764 \mathrm{ppm}$ suggested the attribution of the proton of the $\mathrm{CH}=\mathrm{N}$ group, the singlet signal at $\delta=9.352 \mathrm{ppm}$ suggested the attribution of the proton of the $\mathrm{NH}$ group, and the singlet signal at $\delta=10.525 \mathrm{ppm}$ suggested the attribution of the proton of the $\mathrm{OH}$ group.

Also, the ${ }^{1} \mathrm{H}$-NMR spectrum of compound (5) showed the following characteristic chemical shifts (DMSO as a solvent): the singlet signal at $\delta=2.200 \mathrm{ppm}$ suggested the attribution of the protons of the $\mathrm{CH}_{3}$ group, the singlet signal at $\delta=5.833 \mathrm{ppm}$ suggested the attribution of the proton of $\mathrm{CH}$ of the isoxazole ring, the multiplet signal at $\delta=6.789$ to $7.749 \mathrm{ppm}$ suggested the attribution of the protons of two aromatic benzene rings, the singlet signal at $\delta=8.698 \mathrm{ppm}$ suggested the attribution of the proton of the $\mathrm{CH}=\mathrm{N}$ group, and the singlet signal at $\delta=9.602 \mathrm{ppm}$ suggested the attribution of the proton of the NH group [15], as shown in Table 4.

\section{Experimental}

A solution of sulfamethoxazole $(0.001 \mathrm{~mol})$ in absolute ethanol $(30 \mathrm{ml})$ was slowly added to a solution of aldehyde $(0.001 \mathrm{~mol})$ in absolute ethanol $(20 \mathrm{ml})$. The stirred reaction mixture was refluxed for $12 \mathrm{~h}$. After cooling, a precipitate was formed which was collected by filtration, then washed with cold ethanol, and recrystallized from ethanol.

Table $4{ }^{\mathbf{1}} \mathrm{H}$-NMR data of sulfamethoxazole and its derivatives

\begin{tabular}{lcccccc}
\hline Compounds & $\mathrm{CH}_{3}$ & $\begin{array}{c}\mathrm{C}-\mathrm{H} \\
\text { isoxazole } \\
\text { ring }\end{array}$ & $\begin{array}{c}\text { Aromatic } \\
\text { benzene } \\
\text { rings }\end{array}$ & Imine & $\mathbf{N}-\mathbf{H}$ & $\mathrm{OH}$ \\
\hline$(1)$ & 2.212 & 6.029 & 6.743 to 7.768 & 8.764 & 9.352 & 10.525 \\
$(5)$ & 2.200 & 5.833 & 6.789 to 7.749 & 8.698 & 9.602 & - \\
\hline
\end{tabular}




\section{Conclusion}

Five Schiffs bases: (1), (2), (3), (4), and (5), were synthesized as derivatives of sulfamethoxazole and characterized by UV, FTIR, and ${ }^{1} \mathrm{H}-\mathrm{NMR}$ spectroscopies and elemental analysis (CHNS).

\section{Competing interests}

The authors declare that they have no competing interests.

\section{Acknowledgements}

The authors acknowledge the Department of Chemistry, College of Science, Al-Nahrain University for their encouragement.

\section{Author details}

'Department of Chemistry, College of Science for Women, Baghdad University, Baghdad, Iraq. ${ }^{2}$ Department of Chemistry, College of Science, Al-Nahrain University, Baghdad, Iraq.

Received: 5 January 2014 Accepted: 18 February 2014

Published: 28 February 2014

\section{References}

1. Arulmurugan S, Kavitha PH, Venkatraman RP (2010) Biological activities of Schiff base and its complexes: a review. Rasayan J Chem 3(3):385-410

2. Schiff H (1864) Mitteilungen aus dem universitats laboratorium in Pisa: Eineneue reihe organischer basen. Justus Liebigs Ann Chem 131:118-119

3. Dhar DN, Taploo CL (1982) Schiff bases and their applications. J Sci Ind Res 41:501-506

4. Przybylski P, Huczyński A, Pyta K, Brzezinski B, Bartl F (2009) Biological properties of Schiff bases and azo derivatives of phenols. Curr Org Chem 13:124-148

5. Bringmann G, Dreyer M, Faber JH, Dalsgaard PW, Staerk D, Jaroszewski JW (2004) Ancistrotanzanine $C$ and related 5,1'- and 7,3'-coupled naphthylisoquinoline alkaloids from Ancistrocladus tanzaniensis. J Nat Prod 67(5):743-748

6. Salimon J, Salih N, Ibraheem H, Yousif E (2010) Synthesis of 2-N-salicylidene5-(substituted)-1,3,4-thiadiazole as potential antimicrobial agents. Asian J Chem 22(7):5289-5296

7. Guo Z, Xing R, Liu S, Zhong Z, Ji X, Wang L (2007) Antifungal properties of Schiff bases of chitosan, N-substituted chitosan and quaternized chitosan. Carbohydr Res 342(10):1329-1332

8. Li Y, Yang ZS, Zhang H, Cao BJ, Wang FD (2003) Artemisinin derivatives bearing Mannich base group: synthesis and antimalarial activity. Bioorg Med Chem 11:4363-4368

9. Yousif E, Salih N, Salimon J (2011) Improvement of the photostabilization of PVC films in the presence of $2 \mathrm{~N}$-salicylidene-5-(substituted)-1,3,4thiadiazole. J Appl Polym Sci 120:2207-2214

10. Yousif E, Ahmed A, Mahmoud M (2012) New organic photostabilizers for rigid PVC against photodegradation. Lambert Academic, Saarbrücken

11. Yousif E (2012) Photostabilization of PVC: principles and applications. Lambert Academic, Saarbrücken

12. Yousif E, Salimon J, Salih N, Ahmed A (2012) Improvement of the photostabilization of PMMA films in the presence $2 \mathrm{~N}$-salicylidene-5(substituted)-1,3,4-thiadiazole. J King Saud University Sci 24:131-137

13. Yousif E, Salimon J, Salih N (2012) New stabilizers for polystyrene based on 2-N-salicylidene-5-(substituted)-1,3,4-thiadiazole compounds. J Saudi Chem Soc 16:299-306

14. Yousif E, Haddad R, Ahmed A (2013) Photodegradation and photostabilization of polystyrene. Lambert Academic, Saarbrücken

15. Haddad R, Yousif E, Ahmed A (2013) Synthesis and characterization of transition metal complexes of 4-amino-5-pyridyl-4H-1,2,4-triazole-3-thiol. Springerplus 2:510

doi:10.1186/2191-2858-4-1

Cite this article as: Hussain et al: Synthesis and characterization of Schiff's bases of sulfamethoxazole. Organic and Medicinal Chemistry Letters 2014 4:1.

\section{Submit your manuscript to a SpringerOpen ${ }^{\odot}$ journal and benefit from:}

- Convenient online submission

- Rigorous peer review

- Immediate publication on acceptance

- Open access: articles freely available online

- High visibility within the field

- Retaining the copyright to your article

Submit your next manuscript at $\gg$ springeropen.com 